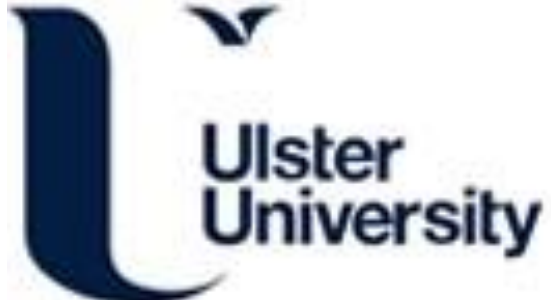

\section{Review of ICT-Based Services for Identified Unmet Needs in People with Dementia}

Lauriks, S., Reinersmann, A., van der Roest, H. G., Meiland, F., Davies, RJ., Moelaert, F., Mulvenna, M., Nugent, CD., \& Dröes, R. M. (2010). Review of ICT-Based Services for Identified Unmet Needs in People with Dementia. In M. Mulvenna, \& CD. Nugent (Eds.), Supporting People with Dementia Using Pervasive Health Technologies (pp. 37-62). Springer. https://doi.org/10.1007/978-1-84882-551-2

Link to publication record in Ulster University Research Portal

Published in:

Supporting People with Dementia Using Pervasive Health Technologies

Publication Status:

Published (in print/issue): 01/01/2010

DOI:

10.1007/978-1-84882-551-2

\section{Document Version}

Publisher's PDF, also known as Version of record

\section{General rights}

Copyright for the publications made accessible via Ulster University's Research Portal is retained by the author(s) and / or other copyright owners and it is a condition of accessing these publications that users recognise and abide by the legal requirements associated with these rights.

\section{Take down policy}

The Research Portal is Ulster University's institutional repository that provides access to Ulster's research outputs. Every effort has been made to ensure that content in the Research Portal does not infringe any person's rights, or applicable UK laws. If you discover content in the Research Portal that you believe breaches copyright or violates any law, please contact pure-support@ulster.ac.uk. 


\title{
Chapter 4 \\ Review of ICT-Based Services for Identified Unmet Needs in People with Dementia
}

\author{
Steve Lauriks, Annika Reinersmann, Henriëtte Geralde van der Roest, \\ Franka Meiland, Richard Davies, Ferial Moelaert, Maurice D. Mulvenna, \\ Chris D. Nugent, and Rose-Marie Dröes
}

\begin{abstract}
Some of the needs that people with dementia and their informal carers currently perceive as insufficiently met by regular care and support services might be alleviated, or even be met, using modern Information and Communication Technology (ICT). The study described in this chapter was designed to provide an insight into the state of the art in ICT solutions that could contribute to meet the most frequently mentioned unmet needs by people with dementia and their informal carers. These needs can be summarized as (1) the need for general and personalized information; (2) the need for support with regard to symptoms of dementia; (3) the need for social contact and company; and (4) the need for health monitoring and perceived safety. Databases that were searched include PubMed, Cinahl, Psychinfo, Google (Scholar), INSPEC and IEEE. In total 22 websites and 46 publications were included that satisfied the following criteria: the article reports on people with dementia and/or their informal carers and discusses an ICT device that has been tested within the target group and has proven to be helpful. Within the first need area 18 relevant websites and three studies were included; within the second need area 4 websites and 20 publications were included. Within the third and fourth need area 11 and 12 publications were included, respectively. Most articles reported on uncontrolled studies. It is concluded that the informational websites offer helpful information for carers but seem less attuned to the person with dementia and do not offer personalized information. ICT solutions aimed at compensating for disabilities, such as memory problems and daily activities, demonstrate that people with mild to moderate dementia are capable of handling simple electronic equipment and can benefit from it in terms of more confidence and enhanced positive affect. Instrumental ICT support for coping with behavioural
\end{abstract}

\footnotetext{
S. Lauriks $(\bowtie)$

Academic Department of Psychiatry, Regional Institute for Mental Health Services GGZBuitenamstel Geestgronden/EMGO-Institute, VU University Medical Center, Amsterdam, The Netherlands

e-mail: s.lauriks@gmail.com
}

This chapter is an abridged version of Lauriks et al. (2007). 
and psychological changes in dementia is relatively disregarded as yet, while support for social contact can be effectively realized through, for example, simplified (mobile) phones or videophones or (entertainment) robots. GPS technology and monitoring systems are proven to result in enhanced feelings of safety and less fear and anxiety. Though these results are promising, more controlled studies in which the developed ICT solutions are tested in real-life situations are needed before implementing them in the care for people with dementia. It is recommended that future studies also focus on the integration of the current techniques and solutions.

\subsection{Introduction}

As the population in our society is ageing, the number of people with chronic diseases is growing. To serve this growing group in an effective and efficient way, more specific knowledge of the needs of people with chronic diseases, as well as of individual variations in needs within different groups of people with chronic disease, is required. One of these groups is people with dementia, whose numbers are expected to double over the next two decades (Ferri et al. 2005). Most of the people with dementia live in the community and are supported by family and friends and professional carers and services. A minority live in institutions such as homes for the elderly, sheltered housing projects and nursing homes (Health Council of the Netherlands 2002; Ferri et al. 2005).

People with dementia have many needs during the progression of their disease, varying from memory support in mild dementia to support in almost all aspects of daily functioning in severe dementia. Family carers, neighbours and friends meet some of these needs, while professional carers meet others. However, despite the efforts of these informal and formal carers, not all the needs of people with dementia can be met. The reasons for this include the limited time that both informal and formal carers have available, and the lack of, or limited availability of, professional services attuned specifically to the concrete needs of individual people with dementia.

A recent gap analysis in two regions of The Netherlands (Amsterdam and Nijmegen) showed that various types of services are available for all of the most frequently mentioned unmet needs (Dröes et al. 2005b). Several possible reasons were mentioned to explain the fact that these needs are still perceived as unmet by people with dementia and their carers. For example, patient and carer (or even professional referrers) are not aware of the service offering that is available; they experience a threshold for using professional services; there are mismatches between the way in which services are offered and the individual needs of patients and/or carers. These reasons are confirmed in the literature, where Coe and Neufeld (1999) conclude 
that most people do not know where to go for help and that they have to take the initiative to find it. As one carer expresses "There is help if you just go after it. The help doesn't find you. You have to go after the help." (p. 575). Cox (1997) and Brodaty et al. (2005) reported that carers who did not use respite services felt they did not really need them, while Koffmann and Taylor (1997) observed that carers experienced guilt when letting their loved ones go into respite care. Also, Winslow (2003) describes barriers to service use, such as care receiver resistance, reluctance of the carer, hassles for the carer, concerns over quality and concerns over finances. Finally, the way in which the professional support is offered (intensity, frequency, flexibility, timing and location) does not always match the different individual needs (Koffmann and Taylor 1997; Gwyther 1998; Coe and Neufeld 1999; Perry and Bontinen 2001; Clare 2002). This often applies for standardized, and therefore non-flexible and non-personalized, care activities and programs. Biegel et al. (1993) found that people with dementia who do not use services or only in-home services were more functionally impaired and had inadequate informal support and more emotionally strained carers compared with users of out-of-home or both in- and out-of-home services. Coe and Neufeld (1999) describe the obstacles carers encounter when they have finally found the help they needed, “(...) for example, there was a delay in obtaining formal help, policies restricted the assistance that could be provided, and the application process was long and complex." (p. 575).

The need for more flexible, personalized care and support is fully in line with the emphasis in the literature for many years that individual needs of patients and carers can considerably differ because of a number of personal and contextual factors, such as the symptoms of the person with dementia, carer characteristics and utilized coping strategies, the relationship between the carer and the person with dementia, the support systems available to the carer and the perception of the quality of the relief that is offered (Duijnstee 1992; Dröes et al. 1996; Dunkin and Anderson-Hanley 1998; Burns 2000; Proctor and Testad 2005; Clare 2002).

Some of the needs that people with dementia and their informal carers currently perceive as insufficiently met by regular care and support services might be alleviated, or even be met, using modern Information and Communication Technology (ICT). In this chapter, we report on a review study that was aimed at getting insight into the state of the art of ICT solutions (in practice and research) that could contribute to meet these unmet needs of people with dementia and their informal carers. Based on the most frequently mentioned unmet needs by people with dementia and by their informal carers that were inventoried in field research among the target group (Dröes et al. 2006; Hancock et al. 2006; van der Roest et al. (2009), we focused our review study at the following need areas: (1) need for general and personalized information; (2) need for support with regard to symptoms of dementia; (3) need for social contact and company; and (4) need for health monitoring and perceived safety. 


\subsection{Method}

\subsubsection{Selection Criteria}

Within the four selected areas of needs a further subdivision into more specific themes was made (see Table 4.1) based on concrete needs mentioned by people with dementia in these areas, as described in the literature (van der Roest et al. 2007) and in three recent field studies that identified both met and unmet needs in people with dementia and their informal and formal carers. Dröes et al. (2006) inventoried general needs with respect to quality of life among people with dementia who attend meeting centres and regular day care centres $(n=106)$ or who live in nursing homes $(n=37)$. Hancock et al. (2006) researched unmet needs of people with dementia $(n=238)$ in residential care using the Camberwell Assessment of Needs for the Elderly (CANE; Cummings et al. 1994). van der Roest et al. (2009)

Table 4.1 Studied need areas and themes

\begin{tabular}{|c|c|}
\hline Needs areas & Specific themes \\
\hline $\begin{array}{l}\text { 1. Need for general and } \\
\text { personalized } \\
\text { information }\end{array}$ & $\begin{array}{l}\text { A. Information on dementia } \\
\text { B. Information on service offerings } \\
\text { C. Information on legal and financial issues } \\
\text { and on care and support services } \\
\text { D. Information on personal condition, care } \\
\quad \text { appointments and care planning }\end{array}$ \\
\hline $\begin{array}{l}\text { 2. Need for support } \\
\text { with regard to } \\
\text { symptoms of } \\
\text { dementia }\end{array}$ & $\begin{array}{l}\text { A. ICT compensation for disabilities such } \\
\text { as memory problems in daily life } \\
\text { activities } \\
\text { B. ICT supporting the carer, flexibly and } \\
\text { personalized, in providing instrumental } \\
\text { care to the person with dementia } \\
\text { C. ICT support for people with dementia } \\
\text { and carers regarding behavioural and } \\
\text { psychological changes and how to cope } \\
\text { with them } \\
\text { D. Emotional support for patients and carers }\end{array}$ \\
\hline $\begin{array}{l}\text { 3. The need for social } \\
\text { contact and } \\
\text { company for the } \\
\text { person with } \\
\text { dementia }\end{array}$ & $\begin{array}{l}\text { Ways to stay connected with family, friends } \\
\text { and the social environment and to be } \\
\text { useful }\end{array}$ \\
\hline $\begin{array}{l}\text { 4. The need for health } \\
\text { monitoring and } \\
\text { perceived safety for } \\
\text { the person with } \\
\text { dementia }\end{array}$ & $\begin{array}{l}\text { The need to be cared for and to be safe } \\
\text { when the disease progresses }\end{array}$ \\
\hline
\end{tabular}


conducted a large field study among 236 people with dementia living in the community and 322 carers using the Dutch version of the CANE (Dröes et al. 2004) and in-depth interviews.

From these studies it is clear that the need for general and personalized information mentioned by people with dementia refers to information on the diagnosis, condition, available support services (including information on support, for example, memory problems) and care appointments. Informal carers want information on diagnosis, prognosis, treatment, care structures, day care facilities and other services including legal and financial issues. The mentioned need for support with regard to symptoms of dementia refers to all types of instrumental support in daily life activities, including support to participate in activities and supervision/guidance.

The need for social contact and company refers specifically to ways of staying connected with family, friends and the social environment and to feel useful. Reported needs for health monitoring and perceived safety refer to the wish to be cared for and to feel secure when the disease progresses and disabilities increase.

For this review we focused on articles that were published before 15 November 2006 and met the following inclusion criteria:

- the article reports on people with cognitive disabilities related to dementia and/or their informal carers

- the article discusses an ICT device or application that has been tested within the target group

- the ICT device reported on in the article has proven to be helpful for the person with cognitive disabilities related to dementia and/or the informal carer on one of the selected needs areas of this review (see Table 4.1).

\subsubsection{Search Procedure}

We searched the following databases: PubMed, PsychInfo, Cinahl, INSPEC and IEEE. Besides that we searched on the Internet using Google Scholar. Within these searches we used a list of key words for each needs area (see Lauriks et al. 2007). The snowball effect furthermore enabled us to retrieve other publications based on the references in the publications found initially. The search procedure did not reveal information derived from unpublished studies.

\subsubsection{Analysis}

The searches within the mentioned databases initially resulted in 165 publications and websites. The analysis was performed by two groups of researchers: the first group consisted of three people with expertize in the clinical domain (AR, SL, $\mathrm{RMD}$ ); the second group consisted of two people with expertize in information and communication technology (RJD, MDM). All articles were independently assessed with regard to the inclusion criteria by two researchers and compared afterwards. 
In case of discrepancies the articles were considered again until consensus was reached. This resulted in 22 (examples of) relevant websites and 46 articles that satisfied the inclusion criteria for this review. The selected articles were analysed with regard to needs area, research sample and research design, functionality of the ICT solution/device and outcome or results for the target group (for detailed descriptions of the results of these analyses see Lauriks et al. 2007). The content of the selected ICT solutions and devices is described briefly in Section 4.3.

\subsection{Results}

\subsubsection{Need for General and Personalized Information}

In this needs area 18 relevant websites and three publications were found that satisfied the inclusion criteria.

\subsubsection{Information on Dementia}

Larner (2003) demonstrated that the use of the Internet by people with cognitive disorders and their carers is common and may increase involvement of patients in supervising and documenting their own health care.

The websites of Alzheimer associations provide digital information on dementia (e.g. www.alzheimer-europe.org or www.alz.org). Apart from prevalence figures, research information and advice on the practical, social and emotional consequences of the disease, some of these sites offer the opportunity to chat with fellow patients and carers (e.g. www.alzheimer-nederland.nl). A few sites include an informative section for people with dementia themselves (e.g. www.alz.co.uk).

As part of the UK's Alzheimer's Society project "Learning to Live with Dementia", Freeman et al. (2005) set up guidelines for accessible writing and web design for people with mild to moderate dementia. In order to attune (online) text to the needs of people with dementia they designed and evaluated a website in close collaboration with the target users, which improved the accessibility of the website.

The University of Florida provides a specialized website (www.alzonline.net) where carers are offered information on dementia as well as Internet- and telephonebased support and education. The Alzheimer Research Forum (www.alzforum.org) includes detailed information on clinical guidelines, the medical workup, drugs and non-pharmacological therapies for health care professionals, researchers and lay people.

\subsubsection{Information on Service Offerings}

Besides printed guides containing an overview of health care and welfare services, recently online "social charts" have become available in several European 
countries. They provide detailed information on national or regional services for professionals and/or specific patient groups. Social charts are offered by different organizations and therefore vary with regard to target users, ease-of-use and completeness. Some popular Dutch social charts are provided by the National Institute for Public Health and Environment (RIVM: www.kiesbeter.nl), the Trade organization of regional consumer- and patient-interest organizations (www.zorgbelangnederland.nl) and the National society of informal and voluntary carers (MEZZO; www.mantelzorg.nl). The site www.hulpgids.nl focuses on mental health care and contains a database of over 1,200 clinicians, therapists and psychiatrists. More general sites (e.g. www.vraagwijzer.nl and www.2zw-adreswijzer.nl) offer information on health care, welfare, housing, social security, income, education and policy to a broad audience.

Social charts in other countries, such as www.desocialekaart.be in Belgium, www.alzonline.net in the state of Florida and www.aahsa.org in the USA, are in essence not very different, though some, like www.healthfinder.gov, also provide visitors with comprehensive information on the quality of care.

The social charts discussed above are typically quite static, generic (not specifically intended for people with dementia or their carers) and mainly provide a, often incomplete, list of addresses for services in the region. Personalized, contextsensitive and demand-orientated sites which exist for other diagnostics groups (e.g. www.voorlichtingopmaat.nl for rheumatism patients or www.stoppain.org for pain patients) are lacking for people with dementia and their informal carers.

\subsubsection{Information on Legal and Financial Issues and on Care and Support Services}

The websites of ministries responsible for public health, like the Dutch Ministry of Public Health, Welfare and Sports (VWS), offer information on financial issues, legislation, health insurance and other subjects related to financial and legal developments in care and support services (www.denieuwezorgverzekering.nl or www.minvws.nl). With the website www.zorgvoorbeter.nl, which is part of a national action program, the Dutch Ministry of VWS aims to improve quality of care in home care and institutional care for the elderly and disabled by providing transparency, quality indicators and stimulating improvement trajectories in health care organizations. The site also offers descriptions and examples of high-quality care for people with dementia. A telephone service (the "Mantelzorglijn") offers support to informal carers and can also be contacted for legal and financial advice with regard to care and support services.

\subsubsection{Information on Personal Condition, Care Appointments and Care Planning}

In the USA, the Geisinger Health System with its "MyChart" application allows patients to communicate electronically with their medical care providers and view 
selected portions of their Electronic Health Record (EHR) (Hassol et al. 2004). Likewise, the Henry Ford Hospital in Detroit, Michigan has over 50,000 patients using an application called "MyHealth" to view customized health information, obtain lab test results and renew prescriptions online (www.henryford.com).

Recently, a new system called the Patient Access Electronic Record System (PAERS) was trailed in the UK, which allows patients visiting their General Practitioner (GP) to look up their health records and book in for their appointments (Honeyman et al. 2005). It is not reported whether people with dementia or their informal carers use this system.

Although EHRs are applied on a small scale in hospitals, home care organizations and GP networks in many European countries, patients and informal carers have no access to these records yet. As an increasing number of governments demand that an Electronic Medical Dossier (EMD) and, at a later stage, an Electronic Patient Dossier (EPD) need to be available to every party involved, organizations like the Dutch NICTIZ (www.nictiz.nl) work on standardizing information exchange between health care providers. An important emerging standard to exchange basic medical information is the HL7v3 standard. Apart from memory aids (see next paragraph) ICT solutions that inform people with dementia on their personal condition, appointments and care planning are still in the research and development stage.

\subsubsection{Need for Support with Regard to Symptoms of Dementia}

In the needs area support with regard to symptoms of dementia we included four websites and 20 publications.

\subsubsection{ICT Compensation for Disabilities Such as Memory Problems}

To help people with dementia undertake specific types of time-linked tasks (e.g. taking medication, keeping appointments or following a daily schedule) various possibilities of automatic reminders via Electronic Memory Aids (EMAs) are explored (e.g. Kim et al. 2000; Wilson et al. 2001; Hart et al. 2004). Kim et al. (2000) studied the use of a palmtop computer-based memory aid by persons with functional impairments of prospective memory and found this technology to be useful in a high proportion of patients for assisting memory-dependent functions. Hart et al. (2004) conducted a consumer survey study to ascertain experiences and attitudes regarding the use of portable electronic devices as memory and organizational aids. They concluded that these devices are acceptable or desirable for use as compensatory aids by consumers with moderate to severe brain injury. While these initiatives differ in approach, they agree on the usability of memory aids for persons with dementia, the importance of defining their own reminders and of giving them and their informal carers control over the reminders (e.g. Wilson et al. 2001; Inglis et al. 2003). Most researchers recognize the importance of involving informal carers in the implementation of EMAs as carers motivate the person with dementia to use the EMA but also benefit themselves, as use of an EMA by a person with dementia reduces feelings of worry in the informal carer (Szymkowiak et al. 2004). 
Only a few studies have investigated the effect of EMAs for people with dementia (Van den Broek et al. 2000; Zanetti et al. 2000; Wilson et al. 2001.). Most studies are uncontrolled and based on a small sample, but justify hope for future development. Van den Broek et al. (2000) studied the use of the Voice Organizer, a device on which a message can be recorded by the user and that plays it back on a specified date and time. In the patients with memory problems that participated in the study the prospective memory improved directly after the device was taken into use.

Zanetti et al. (2000) asked five patients with Alzheimer's Disease to conduct seven prospective memory tasks on set times with the help of an electronic agenda and compared the effort with a control condition in which the same tasks had to be performed without the electronic agenda. All participants performed significantly better on the memory tasks when using the electronic agenda. Wilson et al. (2001) report on the effectiveness and usability of the "NeuroPage" system (Hersh and Treadgold 1994), a pager system which allows for a large number of reminders and prompts for various activities (www.neuropage.nhs.uk). Within a mixed diagnostic group with memory disorders, including people with dementia, NeuropPage as well as a pocket-computer memory enhancement system were evaluated and found to be workable although motivation and remembering to enter relevant information did limit overall usefulness (Wilson et al. 2001). EMAs appear particularly suited to support prospective memory and, although they are generally more expensive than non-electronic memory aids, require little training (see review Fritschy et al. 2004).

An electronic calendar to aid persons with memory problems or cognitive impairment, called the Forget-Me-Not device, was produced within the European Technology, Ethics and Dementia (TED) project and could be useful for persons who are confused about day and date (Holte et al. 1998). An EMA informing the person verbally, using vocal recordings, of specific appointments or tasks, also showed positive effects (Oriani et al. 2003). Inglis et al. (2003) and Szymkowiak et al. (2004) utilized a Personal Digital Assistant (PDA) to remind users of daily tasks, telephone numbers, appointments and birthdays. Users appreciated the device, though some visually or hearing impaired users preferred a reminder in the form of vibration.

Baruch et al. (2004) observed beneficial effects of computer systems on orientation, feelings of anxiety and independency in a patient suffering from Alzheimer's disease. Computer screens in the bedroom and living room reduced the needed support and the number of night time calls to the informal carer.

Within the multi-national ENABLE project (enabling technologies for people with dementia) 12 existing products (-concepts) were identified and their effectiveness to support memory, improve quality of life and reduce the carer burden was assessed. These assistive technologies were found to facilitate independent living and some devices may reduce anxiety in people with dementia as well as their informal carers (Gilliard and Hagen et al. 2004). EMAs, sometimes combined with interventions like visual imagery, errorless learning or spaced retrieval techniques, proved efficacious in stimulating memory in people with dementia (see review Grandmaison and Simard 2003).

Cognitive intervention is another approach to support people with dementia in their memory function and can be presented utilizing video conference, computerbased, or Internet-based systems. 
In comparing cognitive intervention via a video conference system with faceto-face intervention, Poon et al. (2005) found telemedicine to be feasible, effective on memory, language and attention and highly accepted in people with dementia. Hofman et al. (1996) used an interactive computer-based program to train people with dementia to use a touch screen and showed improved performance in computer-program tasks. To determine the usefulness of an Interactive Multimedia Internet-based System (IMIS) in people with suspected Alzheimer's disease, Tárraga et al. (2006) compared IMIS in combination with an Integrated Psychostimulation Program (IPP) and pharmacological treatment to IPP combined with pharmacological treatment and pharmacological treatment alone. They found both IMIS and IPP to improve cognition and the IMIS program to provide improvement above that seen with IPP alone.

\subsubsection{ICT Supporting the Carer, Flexibly and Personalized, in Instrumental Care}

Formal and informal carers in a number of European and North-American countries utilize forms of telemedicine such as video conferencing, telemonitoring and telecare to create more capacity by reducing travel time and increase quality of care by allowing more frequent contact and quick referrals to a specialist. Several projects aimed to develop telecare home services that enable persons with dementia to live independently and offer support to their informal carers.

The European Fourth Framework Program (FP4) project ACTION (Assisting Carers using Telematics Interventions to meet Older persons Needs) focused on the empowerment of family carers to help maintain autonomy, independence and quality of life in frail elderly. Familiar electronic equipment like TV and telephone was combined with modern ICT to improve carers' coping skills in daily care and emergency interventions and to offer financial information and emotional support (Magnusson et al. 1998). A Swedish contribution to the project comprised a videophone to facilitate communication between health care providers and patients and their families. Magnusson et al. (2002) found that families were quicker to request information, education and support from professional carers and valued the informal support network of family carers to share experiences.

The FP5 project TeleCARE aimed to design and develop a flexible infrastructure of remote supervision and assistance services to facilitate independent lifestyles and to improve quality of life, confidence, well-being and safety in elderly people, including people with dementia. Partial validation was achieved with field assessments involving four classes of potential users including elderly and their relatives and health care providers. However, field tests for fine tuning and acceptance of the technology still need to be carried out (Camarinha-Matos and Asfaramesh 2004). Another telecare project is the "Tunstall telecare system", which can be tailored to suit the needs of people with dementia and protect them from dangers such as wandering, fires and floods (www.tunstalltown.com). 
Within the "Safe-at-home" project, Woolham (2005) conducted a large-scale study into the effect of different items of assistive and telecare technology. An intervention group of 233 people with dementia was compared to a matched control group of 173. After intervention the two groups differed significantly in the number of services received, visits and contact hours per week, resulting in lower costs in the intervention group. The technology was found reliable and a majority of carers reported reduced feelings of concern for a person's safety. Almost half of the carers felt the project had improved the confidence of the user in their ability to look after themselves safely.

The experiences of 19 informal carers with a web-based home monitoring system, consisting of broadband Internet access, an Ethernet card, the Xanboo Smart Home Management system and a cell phone with text messaging, were explored by Kinney et al. (2004) in the SAFE house project. Carers received training on how to use the system prior to installation and were able to use the system during the intervention period of 24 weeks. Researchers reported reduced carer burden. Cellphone alerts facilitated keeping track of loved ones and as relatives called more often, relationships improved (Kinney et al. 2004).

\subsubsection{ICT Support for People with Dementia and Carers with Regard to Behavioural and Psychological Changes and How to Cope with Them}

Information on behavioural and psychological changes in people with dementia, how to cope with them and where to find support can be found on websites of Alzheimer societies (e.g. www.alzheimer-nederland.nl). Alzheimer Nederland also offers a 24-h telephone service for information, support and advice. The Dutch site www.hulpgids.nl offers psychiatric consultation, forum discussions and fellowpatient contact. On www.vraagwijzer.nl one can get help clarifying a health care demand, get advice on adequate care and support in how to receive the desired type of care.

The Geriatric Research, Education and Clinical Centre (GRECC) of the Minneapolis Department of Veteran Affairs Medical Centre offers practical online information on a number of topics related to caring for a patient with dementia (e.g. how to handle a loved one's decline, how to cope with bowel and urinary incontinence) (http://james.psych.umn.edu/ grecc/caring.htm; Long and Williams 2005). The US website www.alzonline.net provides Internet- and telephone-based support and education for people with Alzheimer's disease and other dementias as well as support for their carers. Utilizing training videos and downloadable information, the site offers classes to address a wide range of topics related to dementia care (e.g. medication management, dealing with the stress of caring and performing daily tasks). An initial program evaluation showed reasonable effectiveness of AlzOnline's Positive Caregiving Classes. Carer self-efficacy improved and subjective carer burden was reduced but positive dimensions of the care giving experience and perceptions of time burden in providing care were unaltered (Glueckauf et al. 
2004). The efficacy of "Care-giver's Friend", an Internet-based multimedia support program designed to support family carers employed in the workforce, was tested by Beauchamp et al. (2005) in 299 participants using a pre-test/post-test design. Results showed significant benefits on carer depression and anxiety and improvements in perceived stress, strain and positive aspects of care giving.

Guiding the behaviour (e.g. to go to a day care centre, eat more meals) of people with dementia by music and sung messages output by an IC recorder was found to be highly effective (Yasuda et al. 2006). The researchers suggest that music can have a strong effect on mental stability and the method can easily be applied to other activities of daily life.

\subsubsection{Emotional Support for People with Dementia and Carers}

White and Dorman (2000) analysed the contents of messages posted on an Alzheimer mail group and concluded that the opportunity to share, unburden or vent, is perceived as empowering and helpful to carers. Almost every Alzheimer association offers a website where people with dementia and their carers can join forums, post messages or chat with fellow sufferers (e.g. http://www.alzheimer-nederland.nl, http://www.pick.nl). Many Alzheimer associations also have a 24-h telephone support service for emotional support and information on regional support services like Alzheimer café's and meeting centres.

An Internet-based application called Alzheimer's Carer Internet Support System (ACISS), designed to provide carers with clinical, decision-making and emotional support, was evaluated in a 6-month field trial of 42 carer/patient dyads. Preliminary results showed the system to be beneficial to carers of people with dementia (Vehvilainen et al. 2002).

\subsubsection{Need for Social Contact and Company for the Person with Dementia}

In the need area for social contact and company 11 publications were included. Simplified mobile phones for elderly persons to contact informal carers or relatives directly have recently been developed. Lekeu et al. (2002) demonstrated that people with mild dementia are able to learn how to use a mobile phone with an "errorless learning" method (Clare et al. 2000). The "Mobile Telecoach", a one-button mobile phone which allows direct answering, had an effect on positive social experiences and self-esteem in people with dementia. However, users were not satisfied with its size, weight and battery life (Kort 2005). The FP4 project MORE was aimed at redesigning existing mobile phones and simplifying the user interface to meet the many differing needs of elderly and disabled people. Various MORE-based telephones with an integral GPS function were produced by Benefon, but none of these 
have come into use as navigation support for people with disabilities (Lindström 2005).

Within the FP4 project TASC (Telematic Applications Supporting Cognition), five software modules were developed for supporting persons with developmental disability, brain injury or dementia in information provision, communication, environmental control, planning and time management. The TASC system runs on a standard computer; the modules can be used separately or together, are designed to be compatible with future extensions and can be programmed to fit the needs of an individual user. Usability and functional effectiveness of alpha-versions of the system were trialled with representatives of user groups. The amended system was implemented with 18 users across five validation sites. The field trials indicate that the TASC system can reduce the need for help from others with daily activities, leading to increased independence and quality of life and reduced costs for assistance and institutional care (Ager and Aalykke 2001). The ENABLE project included a number of devices to provide pleasure or comfort and facilitate communication such as a picture gramophone (a do-it-yourself multimedia program), a "My history" device (PC with touch screen showing pictures of people and places with familiar voice narrative) and a pre-programmable telephone (calls initiated by just pressing one large button containing a name or photo). Trials among people with mild to moderate dementia indicate that these assistive technologies can enhance well-being by giving positive experiences and reduce anxiety in people with dementia and their informal carers (Gilliard and Hagen 2004).

The "Musical Memory Lane" built in a 1930s Philco radio cabinet and the "Video Memory Lane" housed in a 1950s television cabinet present nostalgic music and videos to people with Alzheimer's Disease in an easy-to-access, push-button, picture format. Systematic observations indicate that the Memory Lanes have a favourable impact on engagement, stimulate positive affect and activity-related talking, while also reducing fidgeting (Olsen et al. 2000).

"Televisits", contact between elderly people living in a nursing home and their family via a videophone, was demonstrated to promote social contact by Mickus and Luz (2002). In a similar study, Sävenstedt et al. (2003) showed that a videophone as a means of communication between patient and family reduced feelings of guilt in family members, allowed more frequent visits than was possible with face-to-face visits and let family members see the physical and emotional state of the patient on a daily basis. In some cases the conversations were more focused and of better quality than during face-to-face visits. In most cases, however, more emphasis was placed on the family member to direct and lead the conversations which was seen by many as demanding. The relationship between staff and family members improved as a side effect of staff helping the patient use the videophone.

Tamura et al. (2004) found that a motorized toy dog can effectively reduce wandering and agitation after dinner in people with dementia. The robot dog AIBO as well as a motorized toy dog proved to be effective in increasing patient activity and spontaneous speech during occupational therapy. Sakairi (2004) showed that the introduction of AIBO increased the number of utterances in people with dementia. These results indicate that socialization and social activity can increase in the 
presence of a toy dog and AIBO. Alm et al. (2003) suggest that with the use of multimedia as a source of reminiscence, patients exhibit more control of the direction of the conversation. They developed a touch screen display to convey photographs, video or music and compared it to traditional reminiscence methods. The patients using the multimedia system showed stronger and more prolonged engagement during the conversations.

\subsubsection{Need for Health Monitoring and Perceived Safety}

Implementing monitoring technologies and detection devices or alarm systems inside and outside the home of elderly persons is potentially useful to enhance (perceived) safety and security of the person suffering from dementia as well as carers. Over the last few decades, detection devices and alarm systems for health problems and safety have been developed for different diagnostic groups, but we found only 12 studies that investigated the effect of these devices among people with dementia.

In a study comparing four biomechanical activity devices to index wandering, Algase et al. (2003) found the stepwatch particularly able to assess amount and daily course of wandering behaviour in people with dementia. In this context, Boundary alarms (activated by a wristband) or electronic tagging with bracelets and monitoring stations were found to be effective, reliable and successful in detecting wandering as well as reducing patient and carer stress (Blackburn 1988; Miskelly 2004). A bedside monitoring system tested in a hospital setting with three patients with dementia who frequently wandered during the night, additionally provides floor lighting upon wandering detection and relays an alarm to a personal handheld device alerting the carer to the situation so that the necessary intervention can be performed (Masuda et al. 2002). A straying prevention system developed by Lin et al. (2006) can counteract wandering without interfering with the daily life activities of the person suffering from dementia. The system consists of indoor residence monitoring, outdoor activity monitoring, emergency rescue service and remote monitoring that can be accessed via a number of mobile devices such as a mobile phone, PDA, notebook or computer. The indoor monitor detects movement between certain areas within the home. Outdoor activities, accompanied or unaccompanied, are monitored in a pre-set activity area, which is activated by pressing a button on the location tracking device. Messages or alarms, respectively, are generated and forwarded via mobile communication (GSM) if the patient leaves the home environment or the activity area. In case of an emergency, the person with dementia can activate an emergency button which sends a message to the call centre where the situation, location and geographical information and location coordinates are analyzed and relayed to care providers, search teams and family members. Conversely, through the secure remote monitoring facility included in the system, family members or care providers can access patient's location information at any time by logging onto the system. Although it was not tested with patients of the target group, the system was expected to be beneficial in helping locate elderly people with dementia by 11 volunteers who reviewed the system. Paavilainen et al. (2005) tested an active 
social alarm system, IST Vivago ${ }^{\circledR}$ WristCare, which provides continuous telemetric monitoring of the user's activity. Results of this study support the use of telemetric actigraphy in long-term screening and follow-up of elderly subjects for sleep and circadian rhythm-related problems associated with dementia and changes in functional capacity.

A fully automatic multi-sensor system composed of Infra Red (IR) sensors connected to a personal computer installed in a patient's room was evaluated by Chan et al. (2002). This smart tool system proved valid in assessing and recording data on activities such as getting out of bed, mobility and travel patterns of a psychotic patient with moderate cognitive decline and behavioural disorders.

Global Positioning Systems (GPS) can also assist in locating people with dementia. Recently, Miskelly (2005) tested a mobile phone with GPS to help families of dementia sufferers if their relative happens to wander off. The person with dementia carries the mobile phone when leaving the house. If a carer or relative needs to know his or her whereabouts, a 24-h control centre can be called. By getting the coordinates of the phone they can pinpoint the person's location with an accuracy of $5 \mathrm{~m}$, enabling help to be sent quickly.

The suitability of GPS systems for location tracking is highlighted by Shimizu et al. (2000) who developed a system that locates the wandering individual to a range of 100-200 m. The system was tested in various conditions such as adverse weather and close proximity of tall buildings. Results showed that despite these adverse conditions, the location accuracy and frequency were sufficient for application in dementia wandering.

The Personal Handy-phone System, worn by the patient as a pendant, could transmit the patient's position with an accuracy of $60 \mathrm{~m}$ to a personal computer. The computer generates a map of the area, and then automatically sends this map via email to the carer who can view it on a mobile phone (Ogawa et al. 2004).

Applying a user-driven design approach Orpwood et al. (2005) developed and evaluated a smart home environment consisting of different services that aimed to assist people with dementia in various areas. During the night, for example, a lighting system was activated if a patient had left the bed. On returning to bed the lights would fade off after a few minutes. However, failure to return to bed after a predefined period of time would result in the communication system telling the patient that it is night time and they should go to bed. Furthermore, the system communicated to the patients when they approached an exit during the night and verbally reminded the patient to return to bed. Next to night monitoring, the system incorporated a cooking monitor service, detecting problems and potential dangers during the cooking process. During evaluations the cooker monitor worked well. However, it caused some irritation to users when the cooker was turned off under false positive situations.

The "eHealth Strategic Objective" of the Information Society Technologies research program of the European Commission is aiming to create an "intelligent environment" that allows ubiquitous management of each person's health status, assisting patients and health professionals in coping with major health challenges. The focus is on key technologies, such as biosensors and secure communications in 
"smart clothes" and implants, as well as software tools for monitoring and managing health status and patient safety. As far as we know such technologies are not yet being applied and validated for persons with dementia.

\subsection{Conclusion and Discussion}

The aim of this review was to get an overview of ICT solutions that successfully supports people with dementia in the areas of obtaining generalized and personal information, coping with symptoms of dementia, maintaining social contact and company and enhancing (feelings of) safety.

\subsubsection{Available ICT-Based Services per Needs Area}

Based on this literature study we can conclude that digital information on dementia, health companies, services and support offerings or financial and legal issues is provided with varying quality on multiple websites, as well as by digital social charts. A majority of these sites offer useful tips and support for carers but seem less attuned to the person suffering from dementia. This applies to the web design as well as to the information offered. Unfortunately, we did not find research in which the websites were tested on helpfulness for the target group. Additionally, an overriding drawback of all digital information is its generic nature. Demand-orientated, personalized information is still difficult to obtain. As the need for personalized and context-sensitive information clearly exists (van der Roest et al. 2007; van der Roest et al. 2009), future development of digital information systems should take these aspects into account.

In the last decade various ICT solutions were developed to support people with dementia and their carers in their everyday problems that arise from the symptoms associated with dementia. External memory aids in the form of reminders (to take medication or keep appointments) or cognitive interventions with Internet-based multimedia systems, including familiar equipment such as TV or PC, have proven efficacious in stimulating memory as well as enhancing feelings of independence and autonomy in the person with dementia. Several devices were developed to compensate for cognitive disabilities in the ENABLE project (e.g. a cooker usage monitor). All in all, these studies show that persons with dementia are not only capable of handling electronic equipment, but also benefit in terms of more confidence and enhanced positive affect, thereby indirectly reducing the carer's perceived burden. Information and emotional support for carers in coping with dementia symptoms furthermore is available through web forums and chat rooms, videotraining and telephone services. Though web-based interventions seem promising especially to help meeting the various needs of people with dementia and carers in an effective and less time-consuming way, instrumental ICT support for coping with behavioural and psychological changes in dementia is, however, relatively disregarded as yet. People with dementia and their carers have access to 
online information (e.g. site of the Alzheimer Association), support (e.g. "Carer's Friend"; Beauchamp et al. 2005), education (e.g. AlzOnline's Positive Care giving classes; Glueckauf et al. 2004) and advice (e.g. online consultation of psychiatrist on www.hulpgids.nl) on coping with behavioural and psychological changes. However, apart from a study in which recorded music in combination with sung messages was found to be highly effective in guiding the behaviour of people with dementia (Yasuda et al. 2006), no proven successful instrumental ICT solutions for coping with behavioural and psychological changes were found. The integration of different technologies into a combined modular system, as piloted in several European projects such as FP4-TASC and FP5-TeleCARE, looks promising. Patients not only made less use of conventional health services, but also reported less negative feelings. Further effort into integrating different systems into a service bundle delivered to patients is therefore recommended.

Support for social contact and company is realized through simplified mobile phones or videophones, that have been reported to facilitate communication between people with dementia and their family or friends. Enhanced positive affect as well as increased activity and communication levels have been observed with computer software providing music or video memories or robotics, such as a toy dog or an entertainment robot. These technical solutions proved to be easily implemented and of great benefit to the person with dementia and their carers.

Finally, we found several ICT solutions for health monitoring and to enhance perceived safety. GPS technology for tracking wandering or lost persons as well as monitoring systems to detect fire or gas leakage or signal night-time activity allow for unobtrusive yet efficient assessments of safety. Additionally, people with dementia and their carers report enhanced feelings of safety and security and less fear and anxiety. Dissemination and implementation of these systems into households are therefore advisable. The monitoring of biological functions in people with dementia is still in its infancy. Unobtrusive, ubiquitous monitoring and management of a person's health using an "intelligent environment" (e.g. the "eHealth Strategic Objective") seems to have potential for the future but has yet to prove its efficacy in the field.

\subsubsection{Limitations of the Current Study}

In order to make the review study practical a number of limitations are present both in the searching process and the analysis. A first restriction concerned the focus of the study. Only ICT solutions that could contribute to meet the most frequently mentioned unmet needs by people with dementia and their informal carers (see Table 4.1) were included in the study. ICT solutions in other needs areas were therefore not included in this study.

A second restriction limited the searching process to a number of databases which covered both the clinical and technical aspects of the study. The databases PubMed, PsychInfo, Cinahl, INSPEC, IEEE and Google (Scholar) were used in the searching process with a total of 165 articles found. Although this selection may 
have caused us to miss relevant articles, we feel the variety of articles found provides a good overview of the state of the art of ICT solutions for the selected needs of people with dementia.

A third restriction was that we included only articles that reported on ICT solutions that were proven to be helpful for people with dementia and/or their carers and that were published before 15th November 2006. ICT solutions that are currently on the market and potentially useful for the target group, but for which no publications were found on the usefulness for people with dementia and/or their carers, are therefore not included in this review.

\subsubsection{Societal Relevance}

ICT support for needs that are unmet by the present care and welfare services could optimize the care for people with dementia and their carers and thus enhances their quality of life.

Whether people with dementia or their informal carers actually make use of and benefit from available ICT applications and services will partly depend on the attitude of health care professionals towards these solutions (e.g. Larner 2003). People with dementia and their informal carers are most likely to learn about available ICT solutions through their general practitioner, specialist, insurance company or care and welfare organizations. In order to inform their clients well, health care professionals should be aware of current and new ICT developments and services. This review gives an overview of successfully and partially successfully applied ICT solutions for people with dementia and their carers and therefore can help health care professionals to get informed on this subject and transfer this knowledge to their clients.

Not all ICT applications and services on today's market have been tested in advance or applied successfully for people with dementia. Although some untested systems could be beneficial to people with dementia or their carers, one cannot be sure of the efficacy of these systems. Only when the system is installed and in use, will the actual effect become clear, in the worst case causing financial, administrative or emotional difficulties for the end-user. Without pretending to be complete, this review tried to focus specifically on ICT solutions that have been successfully tested on people with dementia or their informal carers and have proven to be helpful. This review can therefore support professionals, people with dementia and their informal carers in selecting a specific solution. The information gathered in this review can also be used by health care professionals, policy makers and account managers of insurance companies to assess whether an application or service should be included in National Health Service packages or should be subsidized from health care funds.

As people with mild to moderate dementia seem capable of expressing their needs and do so from a different perspective than their informal carer (Dröes et al. 2006; van der Roest et al. 2007), ICT solutions should be developed in dialogue with the target users. Feedback from people with dementia and their carers during 
the development process can be used to make the final product better attuned to their needs, more personalized and more helpful (COGKNOW Consortium 2006; Sixsmith et al. 2007).

\subsubsection{Technological Interest and Research Recommendations}

Previous research on ICT solutions that aims to meet the unmet needs of people with dementia and their carers in the need areas we focused on in this review study primarily focused on two areas. Most studies concerned general information on the disease; how to cope with the consequences and service offerings on the one hand, and on the safety and monitoring of the person with dementia in various situations on the other hand. The majority of the latter solutions were particularly concerned with stray prevention and adopted a number of varying techniques to detect or locate the person with dementia when wandering both within and outside of the home environment. In the majority of solutions for stray prevention and detection, a warning system was adopted to alert carers or close family members to particular situations that could pose a risk to the person with dementia. Another area that the research explored was that of social contact and providing a basis for allowing a person with dementia to communicate better with others. The research articles found in this area highlighted the need for technology to allow persons with dementia to improve on their communication skills with others. Two studies showed that by using videophone technology, the quantity and quality of conversations between the person with dementia and others would be enhanced (Mickus and Luz 2002; Savenstedt et al. 2003).

One area that was relatively poorly represented was support for persons with dementia to compensate for their disabilities. Although quite a number of solutions were found for memory problems that could potentially be applicable to person with dementia, for some there was no direct evidence that they were effective in the target group. Therefore, these systems were excluded from the review. In a similar fashion there were a number of systems that aimed to provide help with daily living activities such as brushing your teeth; however, these solutions were never tested on people with dementia and were therefore also excluded from the review. Though successfully applied in a single study (Yasuda et al. 2006), instrumental ICT support for coping with behavioural and psychological symptoms in dementia is relatively disregarded as yet and the same holds for personalized information on the diagnosis, condition and personal care appointments. In summary it can be noted that there is a lack of ICT research conducted for two of the four areas that this review process addresses, namely support for obtaining personalized information and instrumental support for dealing with symptoms of dementia, such as memory problems, behavioural and psychological changes and problems with daily activities.

It is recommended that future studies should concentrate on integrating and applying current techniques and solutions in real-life situations with persons with dementia. This research and development process should be user-driven "to ensure 
that devices and systems are grounded within a thorough understanding of the needs, preferences and desires of potential users" (Sixsmith et al. 2007). Special attention should be given to ICT solutions that provide personalized information; compensate for disabilities such as memory problems; help people with dementia and their carers to cope with the behavioural and psychological changes associated with the dementia; and provide help with daily activities, including pleasant activities (Dröes et al. 2006; Sixsmith et al. 2007). The former two need particular attention in producing new ideas on how technology can be of assistance for the target group. An example of a personalized information service is the dynamic interactive social chart for dementia care (DEM-DISC) that provides people with dementia and their informal and formal carers with tailor-made information on regional and national care and support services (and service bundles) (Dröes et al. 2005a, b). ICT solutions for helping people to cope with behavioural and psychological changes and help with daily activities require selection of existing smart home solutions and the subsequent adaptation and testing of them for persons with dementia. All of the authors of this review participate or are indirectly involved in the COGKNOW project (2006) that aims at helping people with mild dementia navigate through their day. The project focuses on developing integrated ICT solutions for frequently mentioned unmet needs by people with dementia and their carers (Dröes et al. 2006; van der Roest et al. 2007), including memory support, support for social contact and daily activities and support for enhancing feelings of safety.

The majority of the studies found included small user groups and were uncontrolled, which makes it hard to generalize their outcomes. Therefore, a second recommendation would be to test the effectiveness of ICT solutions on a larger scale in, preferably, randomized controlled trials before implementing them in the care for people with dementia.

Acknowledgements The study was conducted within the framework of two projects: the FReeband User eXperience (FRUX) project that was financed by the Dutch Ministry of Economic Affairs under contract BSIK 03025, Dioraphte Foundation, RCOAK, NHDI, Foundation het Zonnehuis and the Alzheimer and Neuropsychiatrie Foundation and the COGKNOW project that is funded by the European Commission's Information Society Technologies (IST) program under grant 034025 .

\section{References}

Ager, A., Aalykke, S. (2001) TASC: A microcomputer support system for persons with cognitive disabilities. British Journal of Educational Technology, 32:373-377.

Algase, D.L., Beattie, E.R.A., Leitsch, S.A., Beel-Bates, C.A. (2003) Biomechanical activity devices to index wandering behaviour in dementia. American Journal of Alzheimer's Disease and Other Dementias, 18:85-92.

Alm, N., Dye, R., Gowans, G., Campbell, J., Astell, A., Ellis, M. (2003). Designing an interface usable by people with dementia. ACM SIGCAPH Computers and the Physically Handicapped, June-September, pp. 156-157.

Baruch, J., Downs, M., Baldwin, C., Bruce, E. (2004). A case study in the use of technology to reassure and support a person with dementia. In: J. Moriarty (ed.) Innovative Practice, Dementia: The International Journal of Social Research and Practice, 3(3):371-392. 
Beauchamp, N., Irvine, A.B., Seeley, J., Johnson, B. (2005) Worksite-based internet multimedia program for family caregivers of persons with dementia. Gerontologist, 45:793-801.

Biegel, D.E., Bass, D.M., Schulz, R., Morycz, R. (1993) Predictors of in-home and out-of-home service use by family caregivers of Alzheimer's disease patients. Journal of Aging and Health, 5:419-438.

Blackburn, P. (1988) Freedom to wander. Nursing Times, 84:54-55.

Brodaty, H., Thomson, C., Thompson, C., Fine, M. (2005) Why caregivers of people with dementia and memory loss don't use services. International Journal of Geriatric Psychiatry, 20:537-546.

Broek, M.D.V.D., Downes, J., Johnson, Z., Dayus, B., Hilton, N. (2000) Evaluation of an electronic memory aid in the neuropsychological rehabilitation of prospective memory deficits. Brain Injury, 14:455-462.

Burns, A. (2000) The burden of Alzheimer's disease. The International Journal of Neuropsychopharmacology, 3:31-38.

Camarinha-Matos, L., Asfaramesh, H. (2004) TeleCARE: Collaborative virtual elderly care support communities. Journal on Information Technology in Healthcare, 2:73-86.

Chan, M., Campo, E., Laval, E., Estève, D. (2002) Validation of a remote monitoring system for the elderly: Application to mobility measurements. Technology and Health Care, 10:391-399.

Clare, L., Wilson, B.A., Carter, G., Breen, K., Gosses, A., Hodges, J.R. (2000) Intervening with everyday memory problems in dementia of Alzheimer type: An errorless learning approach. Journal of Clinical and Experimental Neuropsychology, 22:132-146.

Clare, L. (2002) We'll fight it as long as we can: coping with the onset of Alzheimer's disease. Aging and Mental Health, 6:139-148.

Coe, M., Neufeld, A. (1999) Male caregivers' use of formal support. Western Journal of Nursing Research, 21:568-588.

COGKNOW Consortium. (2006). COGKNOW: Helping people with dementia navigate their day. Description of Work, Project Proposal, EU Contract no. 034025.

Cox, C. (1997) Findings from a state-wide program of respite care: A comparison of service users, stoppers, and nonusers. Gerontologist, 37:511-517.

Cummings, J.L., Mega, M., Gray, K., Rosenberg-Thompson, S., Carusi, D.A., Gornbein, J. (1994) The neuropsychiatric inventory: Comprehensive assessment of psychopathology in dementia. Neurology, 44:2308-2314.

Dröes, R.M., Lindeman, E.M., Breebaart, E., van Tilburg, W. (1996). Determinanten van belasting van verzorgers van mensen die lijden aan dementie. In: R.M. Dröes (ed.) Amsterdamse Ontmoetingscentra; een nieuwe vorm van ondersteuning voor mensen met dementie en hun verzorgers. Eindrapport 1996. Thesis Publishers, Amsterdam, pp. 89-118.

Dröes, R.M., van Hout, H.P.J., van der Ploeg, E.S. (2004). Camberwell Assessment of Need for the Elderly (CANE). Revised version IV. Nederlandse Vertaling. VU Medisch Centrum, Amsterdam.

Dröes, R.M., Meiland, F.J.M., Doruff, C., Varodi, I., Akkermans, H., Baida, Z., Faber, E., Haaker, T., Moelaert, F., Kartseva, V., Tan, Y.H. (2005a) A dynamic interactive social chart in dementia care. Attuning demand and supply in the care for persons with dementia and their carers. In: L. Bos, S. Laxminarayan, A. Marsh (eds.) Medical and Care Compunetics, Studies in Health Technology and Informatics. IOS Press, The Netherlands, England, 2(114):210-220.

Dröes, R.M., Meiland, F.J.M., van der Roest, H.G., Maroccini, R., Slagter, R.S., Baida, Z., Haaker, T., Kartseva, V., Hulstijn, J., Schmieman, R., Akkermans, H., Faber, E., Tan, Y.H. (2005b). Opportunities for we-centric service bundling in dementia care. Freeband FRUX Project, Amsterdam.

Dröes, R.M., Boelens, E.J., Bos, J., Meihuizen, L., Ettema, T.P., Gerritsen, D.L., Hoogeveen, F., de Lange, J., Schölzel-Dorenbos, C. (2006) Quality of life in dementia in perspective; an explorative study of variations in opinions among people with dementia and their professional caregivers, and in literature. Dementia: The International Journal of Social Research and Practice, 5:533-558.

Duijnstee, M. (1992). De belasting van familieleden van dementerenden. Intro, Nijkerk. 
Dunkin, J.J., Anderson-Hanley, C. (1998) Dementia caregiver burden: a review of the literature and guidelines for assessment and intervention. Neurology, 51:S53-S60.

Ferri, C.P., Prince, M., Brayne, C., Brodaty, H., Fratiglioni, L., Ganguli, M., Hall, K., Hasegawa, K., Hendrie, H., Huang, Y., Jorm, A., Mathers, C., Menezes, P.R., Rimmer, E., Scazufca, M. (2005) Global prevalence of dementia: A Delphi consensus study. Lancet, 366:2112-2117.

Freeman, E., Clare, L., Savitch, N., Royan, L., Litherland, R., Lindsay, M. (2005) Improving website accessibility for people with early stage dementia: A preliminary investigation. Aging and Mental Health, 9:442-448.

Fritschy, E.P., Kessels, R.P., Postma, A. (2004) External memory aids for patients with dementia: A literature study on efficacy and applicability. Tijdschr Gerontol Geriatr, 35:234-239.

Gilliard, J., Hagen, I. (2004). Enabling technologies for people with dementia. Cross-National Analysis Report, D4.4.1. QLK6-CT-2000-00653, pp. 1-69.

Glueckauf, R.L., Ketterson, T.U., Loomis, J.S., Dages, P. (2004) Online support and education for dementia caregivers: Overview, utilization, and initial program evaluation. Telemedicine Journal and e-Health, 10:223-232.

Grandmaison, E., Simard, M. (2003) A critical review of memory stimulation programs in Alzheimer's disease. Journal of Neuropsychiatry and Clinical Neurosciences, 15:130-144.

Gwyther, L.P. (1998) Social issues of the Alzheimer's patient and family. American Journal of Medicine, 104:17S-21S.

Hancock, G.A., Woods, B., Challis, D., Orrell, M. (2006) The needs of older people with dementia in residential care. International Journal of Geriatric Psychiatry, 21:43-49.

Hart, T., Buchhofer, R., Vaccaro, M. (2004) Portable electronic devices as memory and organizational aids after traumatic brain injury: A consumer survey study. Journal of Head Trauma Rehabilitation, 19:351-365.

Hassol, A., Walker, J.M., Kidder, D., Rokita, K., Young, D., Pierdon, S., Deitz, D., Kuck, S., Ortiz, E. (2004) Patient experiences and attitudes about access to a patient electronic health care record and linked web messaging. Journal of the American Medical Informatics Association, 11:505-513.

Health Council of the Netherlands. (2002/04) Dementia. The Hague, Health Council of the Netherlands.

Hersh, N.A., Treadgold, L.G. (1994) NeuroPage: The rehabilitation of memory dysfunction by prosthetic memory and cueing. Neurorehabilitation, 4:187-197.

Hofmann, M., Hock, C., Kuhler, A., Muller-Spahn, F. (1996) Interactive computer-based cognitive training in patients with Alzheimer's disease. Journal of Psychiatric Research, 30:493-501.

Holte, T., Hagen, I., Björneby, S. (1998). Evaluation of an electronic calendar as helping aid for persons suffering from memory problems or cognitive impairment. Report of the TED-Group.

Honeyman, A., Cox, B., Fisher, B. (2005) Potential impacts of patient access to their electronic care records. Information for Primary Care, 13:55-60.

Inglis, E.A., Szymkowiak, A., Gregor, P., Newell, A.F., Hine, N., Shah, P., Wilson, B.A., Evans, J. (2003) Issues surrounding the user-centred development of a new interactive memory aid. Universal Access in the Information Society, 2:226-234.

Kim, H.J., Burke, D.T., Dowds, M.M., Jr., Boone, K.A., Park, G.J. (2000) Electronic memory aids for outpatient brain injury: Follow-up findings. Brain Injury, 14:187-196.

Kinney, J., Kart, C.S., Murdoch, L., Conley, C. (2004) Striving to provide safety assistance for families of elders: The SAFE House project. Dementia: The International Journal of Social Research and Practice, 3:351-370.

Koffman, J., Taylor, S. (1997) The needs of caregivers. Elder Care, 9:16-19.

Kort, S. (2005). Mobile coaching. A pilot study into the user-friendliness and effects of Mobile Coaching on the wellbeing of people with dementia and their informal caregivers. Faculty of Psychology, Vrije Universiteit, Amsterdam. 
Larner, A.J. (2003) Use of the internet and of the NHS direct telephone helpline for medical information by a cognitive function clinic population. International Journal of Geriatric Psychiatry, 18:118-122.

Lauriks, S., Reinersmann, A., van der Roest, H., Meiland, F.J.M., Davies, R.J., Moelaert, F., Mulvenna, M.D., Nugent, C.D., Dröes, R.M. (2007 October) Review of ICT-based services for identified unmet needs in people with dementia. Ageing Research Reviews, 6(3):223-246.

Lekeu, F., Wojtasik, V., van der Linden, M., Salmon, E. (2002) Training early Alzheimer patients to use a mobile phone. Acta Neurologica Belgium, 102:114-121.

Lin, C.C., Chiu, M.J., Hsiao, C.C., Lee, R.G., Tsai, Y.S. (2006) Wireless health care service system for elderly with dementia. IEEE Transactions on Information Technology Biomedicine, 10:696-704.

Lindström, J.I. (2005) Navigation, alarming and positioning. A preliminary study conducted in Sweden by the Royal Institute of Technology (KTH), Department of Speech, Music and Hearing, on the Assignment of the National Post and Telecom agency (PTS). PTS-ER-2006-16.

Long, C.O., Williams, J.K. (2005) Exploring Alzheimer's disease on the Web. Nursing, 35:30-31.

Magnusson, L., Berthold, H., Chambers, M., Brito, L., Emery, D., Daly, T. (1998) Using telematics with older people: the ACTION project. Assisting carers using telematics interventions to meet older persons' needs. Nursing Standard, 13:36-40.

Magnusson, L., Hanson, E., Brito, L., Berthold, H., Chambers, M., Daly, T. (2002) Supporting family carers through the use of information and communication technology - the EU project ACTION. International Journal of Nursing Studies, 39:369-381.

Masuda, Y., Yoshimura, T., Nakajima, K., Nambu, M., Hayakawa, T., Tamura, T. (2002) Unconstrained monitoring of prevention of wandering the elderly. In: Engineering in Medicine and Biology, 24th Annual Conference and the Annual Fall Meeting of the Biomedical Engineering Society (EMBS/BMES Conference). Proceedings of the Second Joint, 2:19061907.

Mickus, M.A., Luz, C.C. (2002) Televisits: Sustaining long distance family relationships among institutionalized elders through technology. Aging Mental and Health, 6:387-396.

Miskelly, F. (2004) A novel system of electronic tagging in patients with dementia and wandering. Age and Ageing, 33:304-306.

Miskelly, F. (2005) Electronic tracking of patients with dementia and wandering using mobile phone technology. Age and Ageing, 34:497-499.

Ogawa, H., Yonezawa, Y., Maki, H., Sato, H., Caldwell, W.M. (2004). A mobile phone-based safety support system for wandering elderly persons. In: 26th Annual International Conference of the Engineering in Medicine and Biology Society (EMBC). Conference Proceedings 2: 3316-3317.

Olsen, R.V., Hutchings, B.L., Ehrenkrantz, E. (2000) "Media Memory Lane" interventions in an Alzheimer's day care centre. American Journal of Alzheimer's Disease and Other Dementias, $15: 163-175$.

Oriani, M., Moniz-Cook, E., Binetti, G., Zanieri, G., Frisoni, G.B., Geroldi, C., de Vreese, L.P., Zanetti, O. (2003) An electronic memory aid to support prospective memory in patients in the early stages of Alzheimer's disease: A pilot study. Aging and Mental Health, 7: 22-27.

Orpwood, R., Gibbs, C., Adlam, T., Faulkner, R., Meegahawatte, D. (2005) The design of smart homes for people with dementia - user-interface aspects. Universal Access in the Information Society, 4:156-164.

Paavilainen, P., Korhonen, I., Lotjonen, J., Cluitmans, L., Jylha, M., Sarela, A., Partinen, M. (2005) Circadian activity rhythm in demented and non-demented nursing-home residents measured by telemetric actigraphy. Journal of Sleep Research, 14:61-68.

Perry, J., Bontinen, K. (2001) Evaluation of a weekend respite program for persons with Alzheimer disease. Canadian Journal of Nursing Research, 33:81-95. 
Poon, P., Hui, E., Dai, D., Kwok, T., Woo, J. (2005) Cognitive intervention for community-dwelling older persons with memory problems: Telemedicine versus face-to-face treatment. International Journal of Geriatric Psychiatry, 20:285-286.

Proctor, R., Testad, I. (2005) Carer stress-overview. In: A. Burns (ed.) Standards in Dementia Care. European Dementia Consensus Network Edcon. Taylor \& Francis Group, New York, pp. 241-273.

Sakairi, K. (2004) Research of robot-assisted activity for the elderly with senile dementia in a group home. SICE 2004 Annual Conference, 3:2092-2094.

Savenstedt, S., Brulin, C., Sandman, P.O. (2003) Family members' narrated experiences of communicating via video-phone with patients with dementia staying at a nursing home. Journal of Telemedicine and Telecare, 9:216-220.

Shimizu, K., Kawamura, K., Yamamoto, K. (2000). Location system for dementia wandering. In: 22nd Annual International Conference of the IEEE Engineering in Medicine and Biology Society. Proceedings of the 22nd Annual International Conference of the IEEE, 2:1556-1559.

Sixsmith, A.J., Gibson, R.D., Orpwood, R.D., Torrington, J.M. (2007) Developing a technology 'wish-list' to enhance the quality of life of people with dementia. Gerontechnology, 6:2-19.

Szymkowiak, A., Morrison, K., Shah, P., Gregor, P., Evans, J., Newell, A.F., Wilson, B.A., Shofield, S. (2004). Memojog - an interactive memory aid with remote communication. In: S. Keates, J. Clarkson, P. Langdon, P. Robinson (eds.) Designing a More Inclusive World. Proceedings of 2nd Cambridge Workshop on Universal Access and Assistive Technology (CWUAAT) 22 April 2004, Cambridge, UK, pp. 15-24.

Tamura, T., Yonemitsu, S., Itoh, A., Oikawa, D., Kawakami, A., Higashi, Y., Fujimooto, T., Nakajima, K. (2004) Is an entertainment robot useful in the care of elderly people with severe dementia? Journal of Gerontology Series A: Biological Science and Medical Science, 59:83-85.

Tarraga, L., Boada, M., Modinos, G., Espinosa, A., Diego, S., Morera, A., Guitart, M., Balcells, J., Lopez, O.L., Becker, J.T. (2006) A randomised pilot study to assess the efficacy of an interactive, multimedia tool of cognitive stimulation in Alzheimer's disease. Journal of Neurology, Neurosurgery and Psychiatry, 77:1116-1121.

van der Roest, H.G., Meiland, F.J.M., Maroccini, R., Comijs, H.C., Jonker, C., Dröes, R.M. (June, 2007) Subjective needs of people with dementia: A review of the literature. International Psychogeriatric, 19(3):559-592.

Van der Roest, H.G., Meiland, F.J.M., Comijs, H.C., Jansen, A.P., van Hout, H.P.J. (2009). What do community-dwelling people with dementia need? A survey among those who are known to care and welfare services. International Psychogeriatrics, 21(5):949-965.

Vehvilainen, L.M., Zielstorff, R., Gertman, P.M., Tzeng, M.C., Estey, G. (2002). Alzheimer's Caregiver Internet Support System (ACISS): Evaluating the Feasibility and Effectiveness of Supporting Family Caregivers Virtually. American Medical Informatics Association 2002 Symposium, 11 November 2002. S32 Poster Session 1.

White, M.H., Dorman, S.M. (2000) Online support for caregivers: Analysis of an internet Alzheimer mailgroup. Computers in Nursing, 18:168-176.

Wilson, B.A., Emslie, H.C., Quirk, K., Evans, J.J. (2001) Reducing everyday memory and planning problems by means of a paging system: A randomised control crossover study. Journal of Neurology, Neurosurgery and Psychiatry, 70:477-482.

Winslow, B.W. (2003) Family caregivers' experiences with community services: A qualitative analysis. Public Health in Nursing, 20:341-348.

Woolham, J. (2005). Safe at Home. The effectiveness of assistive technology in supporting the independence of people with dementia: The Safe at Home project. Hawker Publications, London. 
Yasuda, K., Beckman, B., Yoneda, M., Yoneda, H., Iwamoto, A., Nakamura, T. (2006) Successful guidance by automatic output of music and verbal messages for daily behavioural disturbances of three individuals with dementia. Neuropsychological Rehabilation, 16:66-82.

Zanetti, O., Zanieri, G., Vreese, L.Pd., Frisoni, G.B., Binetti, G., Trabucchi, M. (2000). Utilizing an electronic memory aid with Alzheimer's disease patients. A study of feasibility. Paper presented at the 6th International Stockholm/Springfield Symposium on Advances in Alzheimer Therapy. 